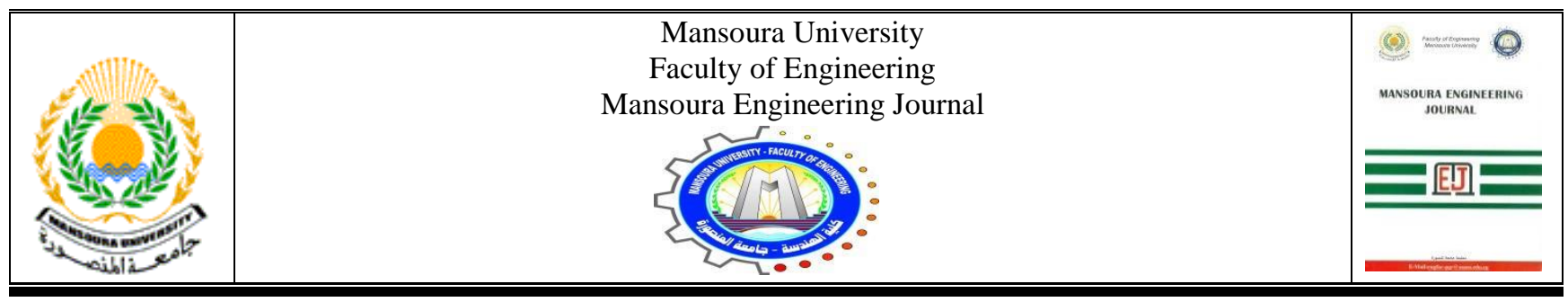

\title{
Design of a Smart Push Pull Inverter Coupled with Photovoltaic System
}

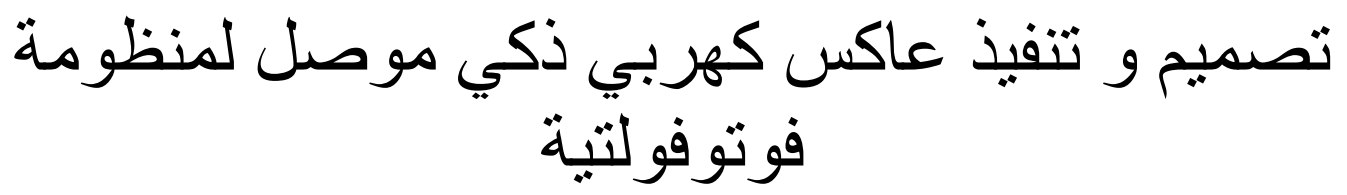

Eid Gouda, Ahmed Abdelhaleim, S. S. Eskander

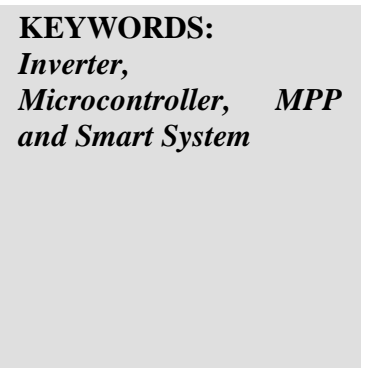

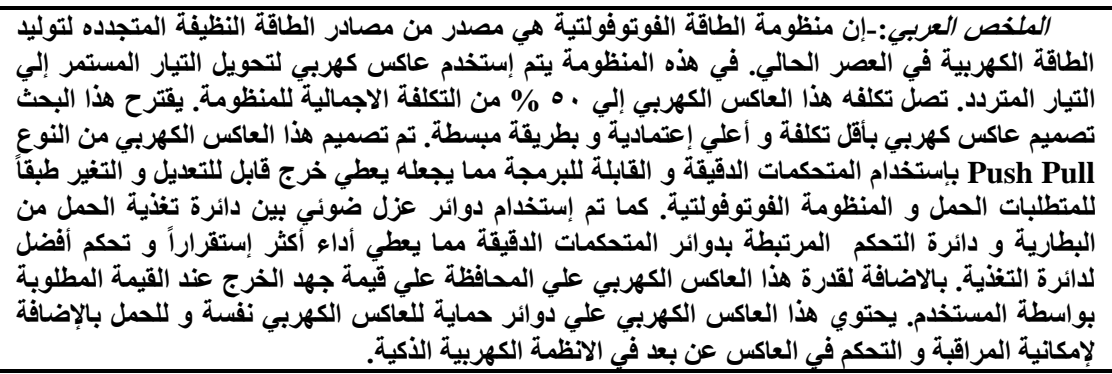

\begin{abstract}
Although the photovoltaic (PV) system plays an important role to meet our needs of an electrical energy, it represents a direct current (DC) source. So, it is not suitable for alternating current (AC) residential loads. This paper proposes a design and practical implementation for a smart single phase low cost inverter, which could be an effective solution to reduce the overall cost of the PV system and supply AC loads. The low cost inverter is achieved by designing low cost control and power circuits. In the power circuit, PV modules operate near the maximum power point (MPP) and supply AC load requirements through the inverter switches. The control circuit uses a microcontroller which provides a smart system for interaction with the user and remote control and monitoring, in addition to use a digital control to maintain the AC output voltage at the required value.
\end{abstract}

\section{INTRODUCTION}

$\mathrm{T}$ There are two general types of inverters: current source inverter and voltage source inverter. The voltage source inverter has a fixed input voltage and is more popular and widely applied in photovoltaic, wind power generation, and other forms of renewable power 2016

Received: 31 March, 2016 - revised: 13 April, 2016 - accepted: 23 May,

Eid Gouda, Electrical engineering department, Mansoura University. (Email: eid.gouda@yahoo.fr)

Ahmed Abdelhaleim, Electrical engineering department, Mansoura University. (E-mail: ahmed.m.abdelhaleim@mans.edu.eg)

S. S. Eskander, Electrical engineering department, Mansoura University generation. For the voltage-source inverter whose input voltage is fixed, its output voltage level can be controlled [1]-[4].

Single-phase voltage-source inverters can be built in the following three topologies. Firstly, the half bridge inverters consists of two large capacitors are required to provide a neutral point, such that each capacitor maintains a constant voltage which equals to half of input DC voltage. So a set of large capacitors is required [5]-[7]. Secondly, Full bridge (Hbridge) inverter is similar to the half-bridge inverter; however, a second leg provides the neutral point to the load [8] - [10]. Thirdly, a Push-pull inverter consists of only two switches and three terminal power transformers. The cost of the push pull inverter depends only on the two power electronics switches, instead of four switches in single phase full bridge inverter, where each switch requires driver circuit, and control signal, and protection circuit. Also, the other main component in the push pull inverter is its transformer which is similar to the transformer of full bridge inverter except that the push pull transformer has two primary windings with half of the rating of the primary winding in full bridge inverter [11]-[16].

The simplest switching scheme for the push pull converter produces a square wave output voltage. The periodic switching of the load voltage between $+\mathrm{Vdc}$ and $-\mathrm{Vdc}$ produces a square wave voltage across the load. Although this alternating output is non-sinusoidal, it may be an adequate AC waveform for some applications. On other hand, Pulse Width 


\section{E: 12 EID GOUDA, AHMED ABDELHALEIM AND S. S. ESKANDER}

Modulation (PWM) control scheme is complex, but its output can become sinusoidal with small filters [17] - [21].

The main goal of this paper is to design and implement a smart push pull inverter for PV supplied homes. It's known that the lighting loads, fans, refrigerator and water pump represent the main different types of domestic loads. Table 1 contains the active power rating and the power factor for each load. These loads operate on $220 \mathrm{~V}, 50 \mathrm{~Hz}$ AC power system. Also the total apparent power is calculated for all the loads to calculate rating of different components in PV power system. This table shows that the total load on the system is 2356 VA. Therefore, this paper discusses the design of a system with rating $2500 \mathrm{VA}$.

This paper is divided into 5 main sections. An introduction was represented in section 1.The design steps of each component of the proposed inverter such as the used batteries, switches, transformer, power supply circuit, gate driver circuit, protection circuits will be shown in section 2 in detail. The inverter control system, microcontroller coding and remote interactive control system will be located in section 3.The most important section of this paper will be found in sections 4, 5 and 6 where the implementation of the inverter, result discussion and remote monitoring of the control system will be analyzed. Finally a conclusion will be presented in section 7.

TABLE 1

THE LOADS TO BE SUPPLIED BY THE DESIGNED PV SYSTEM [22]

\begin{tabular}{c|c|c|c} 
Load Type & $\begin{array}{c}\text { Active } \\
\text { Power } \\
\text { Rating (W) }\end{array}$ & $\begin{array}{c}\text { Power factor } \\
\cos \boldsymbol{\varphi}\end{array}$ & $\begin{array}{c}\text { Apparent } \\
\text { Power (VA) }\end{array}$ \\
\hline Refrigerator & 800 & 0.65 & 1231 \\
\hline Fan & 65 & 0.7 & 93 \\
\hline Tube Light & 50 & 0.5 & 100 \\
\hline Water Pump & 745 & 0.8 & 932 \\
\hline \hline Total Load & 1660 & & 2356
\end{tabular}

\section{INVERTER DESIGN}

Figure 1(a) shows the block diagram of the proposed power inverter within the PV system. The design of the inverter circuits will include sizing the DC batteries or the DC voltage system. Then, the choosing of suitable semiconductor switches for the inverter will be discussed. And, the power transformer will be designed. Also, the design of a gate driver circuits for the inverter switches and their power supply circuits are discussed. Moreover, the design of protection devices for the inverter system is included. The schematic diagram of this inverter system is shown in figure 1(b). And, figure 1(c) shows a photograph for the final connection of the different components in the designed inverter.

\subsection{Batteries}

A battery is a storage vessel for electricity. Deep cycle batteries are the key component in various types of renewable energy systems that require the storage of electricity. A deep cycle battery is designed to discharge between $45 \%$ and $75 \%$ of its capacity, depending on the manufacturer and the construction of the battery. The mean value

$60 \%$ depth of discharge can be used in sizing of DC batteries required for the load. In the market, these batteries usually have the following specifications: 12V, and 100Ah [23].

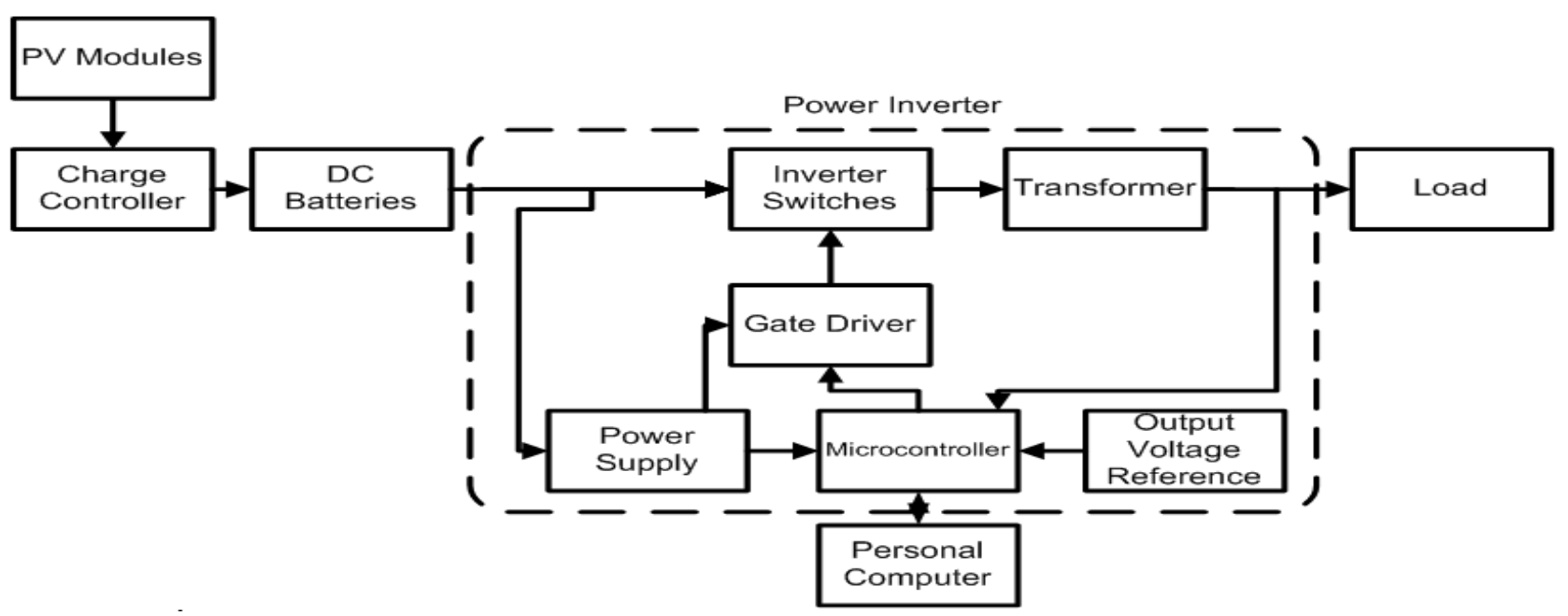

Figure 1 (a) The Proposed Power Inverter System 


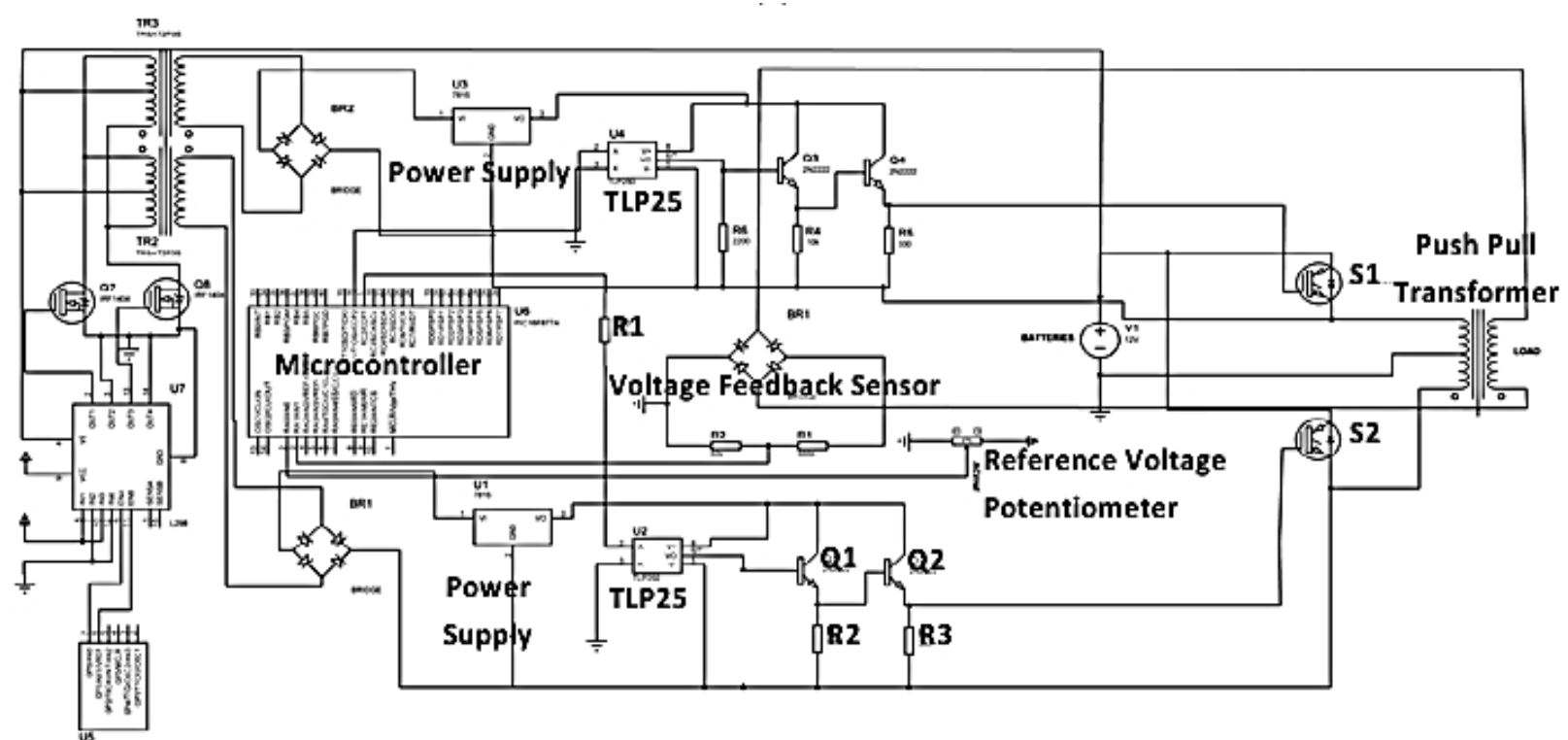

(b)

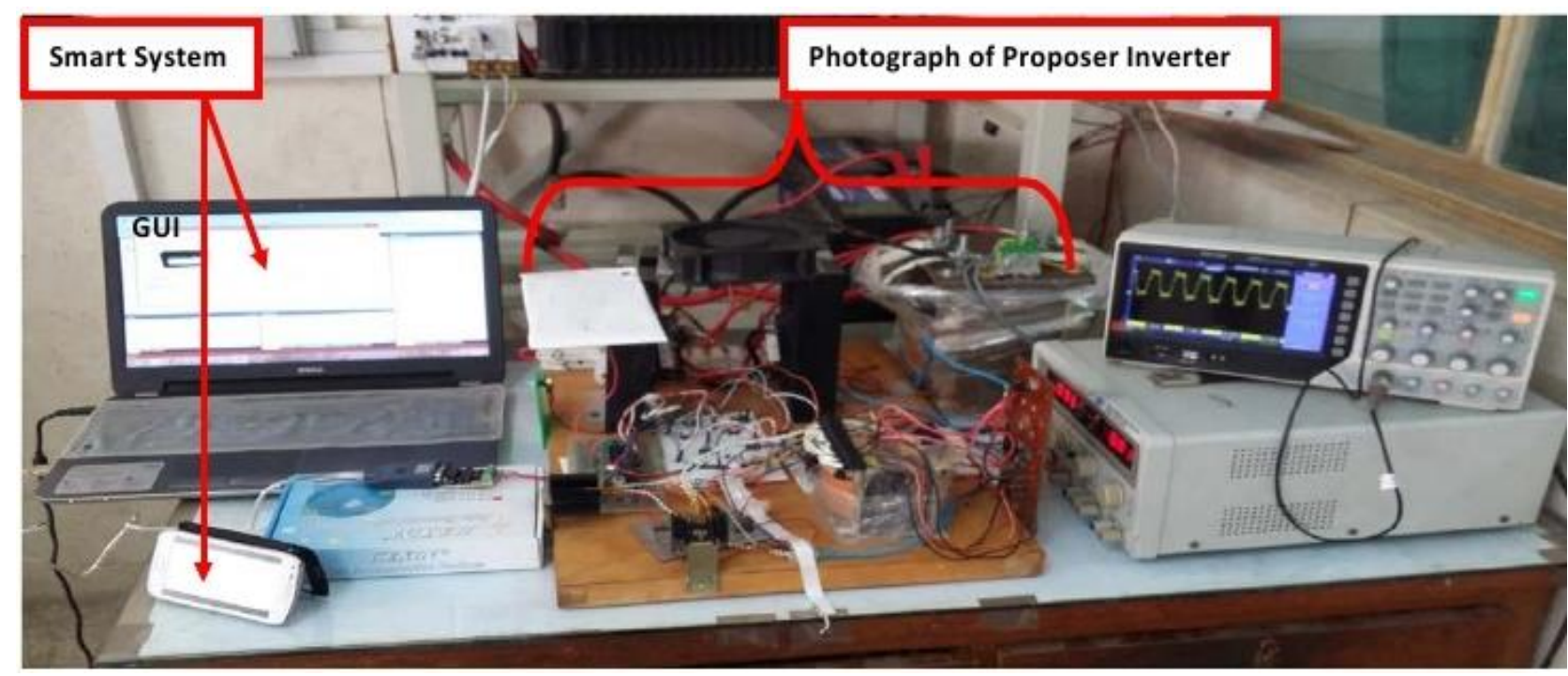

(c)

Figure 1 (b), (c) The Proposed Power Inverter System

Therefore, the DC voltage of the storage system may be $12 \mathrm{~V}$ or its multipliers. In the designed system, the DC system voltage is $24 \mathrm{~V}$ in order to operate the PV modules near the maximum power point, where Vo.c equals to $34.2 \mathrm{~V}$ as stated in the datasheet PV modules.

Designing the capacity of deep cycle batteries depends on the total required energy of the load. Table 2 shows how to calculate the total energy required by the load in one day, assuming that the batteries can be fully charged every day [24]. From table 2, the batteries' capacity is found equals 996.18 Ah which was calculated by dividing the daily total required energy $(14345 \mathrm{Wh})$ by DC system voltage $(24 \mathrm{~V})$ and the battery's depth of discharge (0.6). It is found that 10 parallel batteries are needed for the required capacity. The $24 \mathrm{~V}$ designed system requires 2 series units of batteries.
TABLE 2

TOTAL ENERGY REQUIRED FOR SUPPLYING THE LOADS FOR ONE DAY BY THE DESIGNED PV SYSTEM

\begin{tabular}{c|c|c|c} 
Load Type & $\begin{array}{c}\text { Active } \\
\text { Power } \\
\text { Rating (W) }\end{array}$ & $\begin{array}{c}\text { Time of } \\
\text { Use (h) per } \\
\text { Day }\end{array}$ & $\begin{array}{c}\text { Total } \\
\text { Energy } \\
\text { (Wh) }\end{array}$ \\
\hline Refrigerator & 800 & 12 & 9600 \\
\hline Fan & 65 & 8 & 520 \\
\hline Tube Light & 50 & 10 & 500 \\
\hline Water Pump & 745 & 5 & 3725 \\
\hline \multicolumn{2}{r|}{ Total Energy Required per Day } & 14345
\end{tabular}

\subsection{Inverter Switches}

The push pull inverter has a transformer with two primaries winding which equally share the total load on the inverter. Designing of the inverter switches depends on the half of load current, because each switch is connected directly to one of 
the primary windings of the transformer. The load current can be calculated from equation (1).

$$
\begin{aligned}
& \mathrm{I}=0.5 *(\text { load rating } / \mathrm{DC} \text { System Voltage })= \\
& \frac{2500}{(2 * 24)}=52.1 \mathrm{~A}
\end{aligned}
$$

The IGBT switches are used in this paper, because IGBT switches have higher power capabilities up to $1700 \mathrm{kVA}, 2000$ $\mathrm{V}, 800 \mathrm{~A}$ than the power capabilities of MOSFETs. Also, the heating losses of the IGBT are lower because of its lower resistance than the MOSFET. Their forward voltage drop is 2$3 \mathrm{~V}$. Moreover, this type of switches can withstand the overloading and operates in parallel well due to the negative temperature coefficient. In addition, they have relatively simple voltage controlled gate driver and low gate current. [25], [26].

\subsection{Transformer}

Figure 1(b) shows the transformer which can be used in push-pull inverter. The primary winding of transformer has the following voltage ratings: $24-0-24$ volt. And the voltage rating of the transformer's secondary terminals are $0-260$ volt to allow accessing $220 \mathrm{~V}$ at the output of the inverter during the different loading conditions. The power rating of the transformer is 2500VA [27]. The open circuit test and short circuit test for the transformer were carried out experimentally in order to get the impedances of transformer equivalent circuit. It is found from tests that $x_{m}=4.235 \Omega \mathrm{R}_{\mathrm{fe}}=$ $15.5 \Omega \mathrm{r}_{\mathrm{t}}=0.0143 \Omega$, and $\mathrm{x}_{\mathrm{lt}}=\mathrm{x}_{-} \mathrm{lt}=0.007 \Omega$.

\subsection{Power supply Circuit}

Figure 1(b) displays the schematic diagram of power supply circuit. This circuit is used to convert the $24 \mathrm{~V}$ of the DC batteries into $5 \mathrm{~V}$ for supplying the microcontroller. Also, it converts the $24 \mathrm{~V}$ into $15 \mathrm{~V}$ for the gate driver circuit for the IGBT switches. It consists of voltage regulator, diode, and smoothing capacitor in the output. Designing of the smoothing capacitor depends on the maximum voltage ripple which can occur due to a load on the power supply. The maximum load current on this power supply circuit is the current of driver circuit which reaches to $500 \mathrm{~mA}$ during the ON time of the switches. The smoothing capacitor will supply this maximum current by only $10 \%$ of its amount charge $(\mathrm{Q}=\mathrm{CV})$ in order to achieve fast charging and discharging of capacitor and maintain the output voltage constant. Therefore the capacitance will equal to $2000 \mathrm{uF}$. It is found that the total cost of all components in power circuit of the proposed inverter is nearly $\$ 600$ where the exact costs are in the Appendix.

\subsection{Gate Driver circuit}

In the proposed inverter, the driver circuit depends mainly on TLP250 integrated circuit. This integrated circuit is an optically isolated driver, meaning that the input and output are optically isolated. The TLP250 has an input stage, an output stage and a power supply connection. Table 3 shows the status of the two output transistors depending on the LED in the input stage.

TABLE 3 TLP250 TRUTH TABLE

\begin{tabular}{c|c|c|c} 
& & TR1 & TR2 \\
\hline \multirow{2}{*}{ Input LED } & ON & ON & OFF \\
\cline { 2 - 4 } & OFF & OFF & ON
\end{tabular}

Figure 1(b) shows the schematic diagram for TLP250 driver circuit which is proposed in this paper. Firstly, designing the input stage of TLP250, the input stage consists of LED. LED has an input forward voltage (1.6V) and a peak forward current (10mA). Therefore, R1 will equal $320 \Omega$.

From datasheet of the optocoupler, the maximum collector current of output transistors is $7 \mathrm{~mA}$. Therefore, two transistors Q1, Q2 are required to protect the opotocoupler. Firstly, from the maximum collector current of phototransistors and ohm's law, resistance R2 will equal $2142.86 \Omega$. The nearest standard value resistance equals $2.2 \mathrm{~K} \Omega$, and its power rating must be more than $(14 \mathrm{~mA})^{2} *$ $2.2 * 10^{3}=0.4312$ watt

Providing adequate current for the gate of the IGBT switches entails that the transistor Q2 should be saturated. It is found R3 equals $270 \Omega$ as standard value. The power rating for R3 must be greater than $(100 \mathrm{~mA})^{2} * 270=2.7$ watt.

The TLP250, being an optically isolated driver, has relatively slow propagation delays. The propagation delay time will typically lie between $0.15 \mu$ s and $0.5 \mu$ s. The datasheet specifies the maximum operating frequency to be 25 $\mathrm{kHz}$. Therefore, it is suitable for the proposed inverter in this paper, in which the TLP250 is used for frequencies up to about $50 \mathrm{~Hz}$ in square wave operation.

A $0.1 \mu \mathrm{F}$ bypass capacitor should be connected between pin 8 and pin 5. This capacitor stabilizes the operation of the high gain linear amplifier in the TLP250. Failure to provide this capacitor may impair the switching property. The capacitor should be placed as close to the TLP250 as possible. Added $100 \mu \mathrm{F}$ is for smoothing, as a bulk capacitor.

\subsection{Over Current Protection (Fuses and Circuit Breaker)}

Over current protection is used in both the power and control circuits. Firstly, in control circuit, there are $0.1 \mathrm{~A}$ fuses to protect the driver circuits of the IGBT and microcontroller circuits. Also, a power fuse with rating $40 \mathrm{~A}$ in addition to circuit breaker $63 \mathrm{~A}$ are used to protect the power circuit of the inverters.

\subsection{Snubber Protection Circuits}

Snubber circuit is a supplementary circuit used in the converter circuit to reduce stress put on the power semiconductor device. The ultimate goal of the snubber circuit is to improve the transient waveform. The snubber circuit suppresses over-current or over-voltage. The most common reasons for using a snubber are to limit the peak voltage across the inverter semiconductor switch and to reduce the switching 
loss during turn-off. The snubber circuit has many configurations. The simplest snubber circuit for IGBT in inverter applications is RC snubber circuit [28]. Designing of snubber circuit for IGBT switches can be calculated from the following approximate method [29].

A. - The resistance value is chosen to allow the flow of load current without voltage overshoot after the switch opens. The resistance value calculated from equation (2) depending on Vo and I. Vo is off voltage across the switch after it opens and $\mathrm{I}$ is on current before the switch opens.

$R \leq \frac{V o}{I} \leq \frac{24}{42} \leq 0.57$

B. - The resistance will dissipate the energy stored in the snubber capacitor, $1 / 2 * \mathrm{Cs} * \mathrm{Vo}^{2}$, for each voltage transition regardless of the resistance. The capacitance will be chosen to cause the 7-watt resistor to dissipate half of its power rating, 3.5 watts. For two times $\mathrm{f}_{\mathrm{s}}$ (switching frequency $=1000 \mathrm{HZ}$ ) transitions per second, the resistor will dissipate 3.5 watt. Then, Cs can be calculated from equation (3).

$C_{s}=\frac{3.5}{f_{s} V_{o}^{2}}=6 \mu \mathrm{F}$

\section{INVERTER CONTROL SYSTEM}

The control system of the inverter depends mainly on a microcontroller. Also, there is a connection between the microcontroller and A Personal Computer (PC) which plays a great role in smart systems. This connection allows the user to remote control and monitor for the overall performance of the system in two ways. Firstly, the user can monitor and control the inverter by using a simple Graphical User Interface (GUI) on the PC. Secondly, sending and receiving standard e-mails between the user and the inverter system. This allows the user to know and control the status of the system from any PC or phone. The total cost of control circuit of the proposed inverter is about $\$ 20$ where the exact costs are in the Appendix.

\section{1. Microcontroller Coding}

PIC microcontroller will be programmed to generate the control signals for inverter switches $S \_1$, and $S \_2$ shown in figure 1(b). These control signals are responsible for converting the DC voltage of batteries into $50 \mathrm{HZ}$ AC voltage. Also, changing the duty cycle of the control signal will change the RMS value of output AC voltage from the inverter.

Figure 1(b) shows schematic diagram of microcontroller circuit. Two analogue inputs are used. One of them is used to measure the reference value of $\mathrm{AC}$ output voltage. The second is used to measure a value of actual AC voltage. Then, microcontroller compares

Both values of analogue inputs to give proper control signals.

The program of microcontroller should consider the dead time for the inverter switches. This dead time depends on the inductance of the load. The current $i$ of an inductive load continue after the termination of the load voltage by conduction angle $\beta$ this angle $(\beta)$ will be calculated firstly. Based on this conduction angle and reference voltage input for the microcontroller, the output control signals will be generated by the microcontroller.

Control signal for the square wave inverter consists of two time periods in each half cycle. In each half cycle, the inverter switch $\left(\mathrm{S}_{1}\right.$, or $\left.\mathrm{S}_{2}\right)$ is closed during. $\mathrm{T}_{\text {on }}$ milliseconds and is open during $\mathrm{T}_{\text {off }}$ milliseconds. $\mathrm{T}_{\text {off }}$ for the inverter switches must equal to or greater than the dead time for this load. The dead time is calculated from the conduction angle $\beta$. Then, the calculation of $\mathrm{T}_{\text {off }}$ will depend on dead time, reference voltage, and actual output voltage. Therefore, in microcontroller code, there is minimum value for $\mathrm{T}_{\text {off }}$ This minimum value equals to the calculated the dead time for the load. So the flowchart for the microcontroller code should be as figure 2 .

\section{A. Fuzzy Logic Voltage Stabilization Control Loop}

The calculation of $\mathrm{T}_{\text {off }}$ for the inverter switches depends on a simple fuzzy logic equation (4).

$T_{\text {off }}=\frac{V_{\text {out }}-V_{\text {ref }}}{V_{\text {ref }}} * 10 m s+T_{\text {off }}$

In equation (4), $\mathrm{T}_{\text {off }}$ is calculated based on the initial value for $\mathrm{T}_{\text {off }}$ which equal to the calculated dead time for the load at the beginning of inverter operation. Then, during the operation of inverter, $\mathrm{T}_{\text {off }}$ increases when the output voltage becomes larger than the reference voltage. On the other hand, $\mathrm{T}_{\text {off }}$ decreases based on the percentage error between the output voltage and the reference voltage when the output voltage becomes less than the reference voltage. The maximum value for $\mathrm{T}_{\text {off }}$ is $10 \mathrm{~ms}$ which is the half of a switching period for $50 \mathrm{~Hz}$ output.

\section{B. Calculation of Load Conduction Angle}

Calculation of load conduction angle requires knowing the total impedance seen by the inverter switches. So, firstly, the total impedance of transformer and the load will be calculated. Then, from the current equation of the load, the conduction angle can be calculated. Table 4 shows the calculation of loads impedances and the total load impedance and impedance referred to $24 \mathrm{~V}$ side of the transformer. The total impedance $(\mathrm{Z} \mid \varphi)$ on the inverter can be calculated which is equal to $0.255\left\lfloor 47.2^{\circ}\right.$

The conduction angle angle $\beta$ is calculated from the load current (equation 5) and its value equal 3.93 radian. The dead time equals $2.5 \mathrm{~ms}$ which is calculated by equation (6).

$i=\frac{\sqrt{2} * V * \sin (w t-\varphi)}{Z}+\frac{\sqrt{2} * V * \sin \varphi}{Z} e^{-\frac{R}{L} t}$
Dead time $=(\beta-\pi) * \frac{10 \mathrm{~ms}}{\pi}=2.5 \mathrm{~ms}$ 


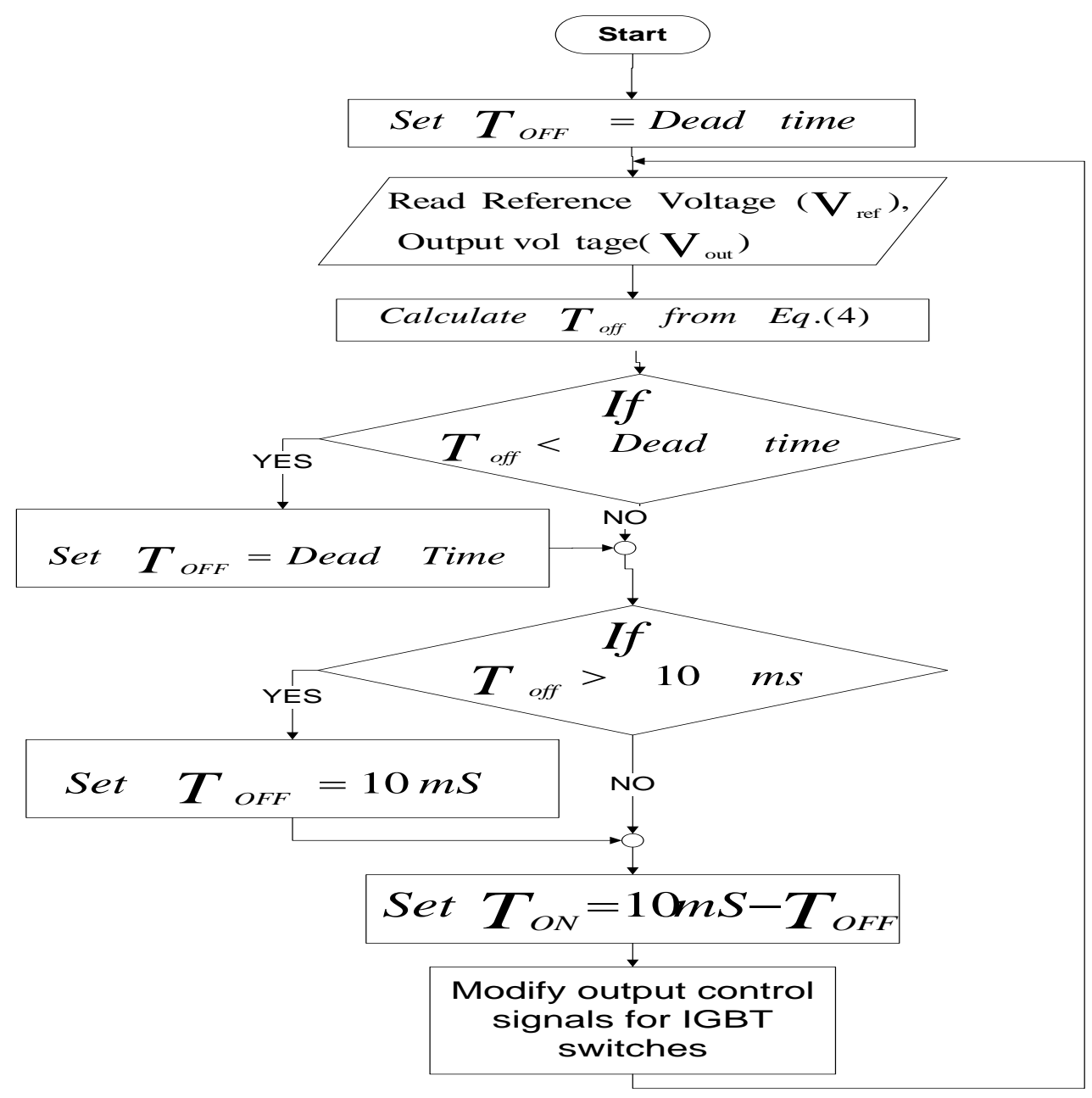

Figure 2 Software Flowchart

\section{2. Remote Interactive Control System}

The Universal Asynchronous Receiver Transmitter (UART) module is the basic serial I/O module available in the microcontroller.

The UART is a full duplex asynchronous system that can communicate with peripheral devices, like personal computers, RS-232, and RS-485 interfaces [29]. The DC batteries voltages, its state of charge, the inverter's output voltage, system state of operation are transmitted from microcontroller to the PC via the UART module. The microcontroller sends this information through its UART module at rate $9600 \mathrm{bps}$ and its logic voltage $0-5 \mathrm{~V}$.

TABLE 4

CAlculation OF TOTAL LOAD IMPEDANCE

\begin{tabular}{|c|c|c|c|c|c|}
\hline Load Type & $\begin{array}{c}\text { Rating } \\
(\mathrm{W})\end{array}$ & $\begin{array}{c}\text { Power } \\
\text { factor } \\
(\cos \varphi)\end{array}$ & $\mathrm{I}(\mathrm{A})$ & $|I|(\mathrm{A})$ & $Z(\Omega)$ \\
\hline Refrigerator & 800 & 0.65 & $3.64-\mathrm{j} 4.25$ & 5.59 & $25.56+\mathrm{j} 29.88$ \\
\hline Fan & 65 & 0.7 & $2.05-\mathrm{j} 2.73$ & 3.41 & $364.9+\mathrm{j} 372.2$ \\
\hline Tube Light & 50 & 0.5 & $0.23-\mathrm{j} 0.394$ & 0.45 & $242+\mathrm{j} 419$ \\
\hline Water Pump & 745 & 0.8 & $3.38-\mathrm{j} 2.5$ & 4.2 & $41.6+\mathrm{j} 31.18$ \\
\hline Total Impedance of Load in Parallel $\left(Z_{L}{ }^{\prime}\right)$ & $14.72+\mathrm{j} 15.573$ \\
\hline \multicolumn{7}{|c|}{$\mathrm{Z}_{\mathrm{L}}=\mathrm{Z}_{\mathrm{L}}{ }^{\prime} *(24 / 220)^{2}$} & $0.1752+\mathrm{j} 0.18533$ \\
\hline
\end{tabular}

Then, the RS232 circuit is used to convert the $0-5 \mathrm{~V}$ signal from the microcontroller into 0-12 $\mathrm{V}$ logic signal which can be read by the PC. By using the serial to USB converter, this microcontroller system can be connected to any PC. Finaly, The PC displays all the information for the user though a GUI which shown in figure 1(c). Also, PC sends an e-mail which contains this displayed information upon the user's request.

\section{IMPLEMENTATION}

The implementation of the proposed inverter includes the following steps:

A. All designed circuits for the inverter are implemented on Printed Circuit Board (PCB) by using PROTEUS DESIGN SUITE program. Figure 3 shows PCB of microcontroller control circuit. 


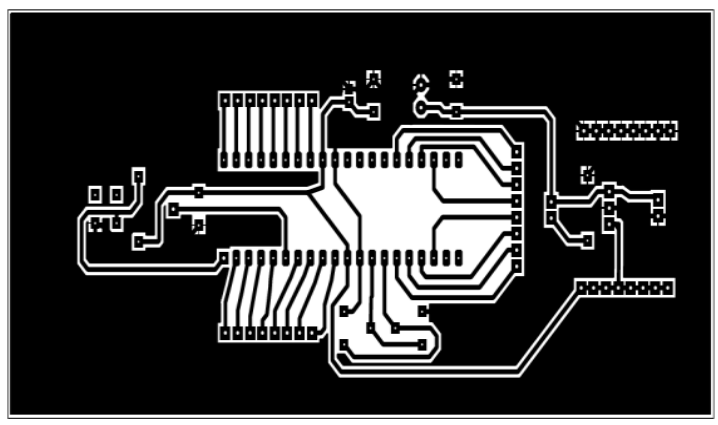

Figure 3 PCB of control circuit

B. $16 \mathrm{~F} 877 \mathrm{~A}$ is used as a microcontroller in the designed system. Because PIC microcontroller require 4 clock cycles for each instruction cycle, an external oscillator circuits for microcontroller can be $4 \mathrm{MHZ}$. It is adequate to generate control signal at frequency $50 \mathrm{HZ}$. This microcontroller is programmed by using MikroC.

C. In order to avoid the saturation of the power transformer, polarity test is conducted to find which terminals of the primary windings will be connected to the same point. And the other terminals are connected to the inverter switches.

D. Two inverter switches are placed in two separate heat sinks. Heat sinks are close to each other in order to be cooled with one fan.

E. In the designed system, $16 \mathrm{~mm}^{\wedge} 2$ cables are used in power circuit. And $0.3 \mathrm{~mm}^{\wedge} 2$ connecting wires are used in control circuits.

F. Crocodile clamps prepared to easily connect DC batteries with inverter.

G. RS232 converter module and USB to (RS-232/RS232) Serial port (male connector) device are used to connect the inverter to the PC. And the PC program is implemented though Microsoft Visual Studio environment by using C\# programming language.

\section{RESULTS AND DISCUSSIONS}

The operation of the proposed system is discussed in the following three sections. The first section discusses the modeling of the inverter. Then, the proposed control system is achieved in practical implementation through using the square wave control in the second section and Pulse Width Modulation (PWM) control for inverter switches is presented in the last section.

\subsection{Results of Inverter State Space Model}

The simulation for inverter output under the proposed control system is investigated by using state space modeling for the proposed inverter. This modeling is solved by using MATLAB and gives the output voltage shown in figure 4(a). The harmonic spectrum for the modeling output voltage is also calculated and plotted in figure 4(b). This spectrum shows that there is no requirement for using a filter.

\subsection{Results of Square Wave Control for Inverter Switches}

For square wave control, the output signals from the driver circuit is shown in figure 4(c) which takes the same shape of the control signals from microcontroller. Figure 4(d) shows the output of the inverter with full load and $220 \mathrm{~V}$ on the output. These outputs waveform is measured by using scale of 38:1. In figure 4(d), points A, B is the limits of one half cycle of the output voltage waveform. The voltage near to points A and $B$ falls to zero, because it represents the calculated $T_{\text {off }}$ of the control signal. Also, it can be noted that the output near point $A$ and $B$ is not still zero during. $T_{\text {off }}$. Near to points $A$ and $\mathrm{B}$, the output voltage is greatly deviate from the sinusoidal shape and largely increase during $\mathrm{T}_{\text {off }}$ due to the fast change in the state of power circuit of inverter. This fast change in output voltage can damage the electrical equipment connected to this system. This output voltage can be investigated also from analyzing its harmonic spectrum. Figure 4(g) displays the harmonics magnitude spectrum for output voltage during $220 \mathrm{~V}$ output voltage with full load. This harmonics magnitude spectrum shows an increase in harmonics more than the expected value from the modeling results. Therefore, it is necessary to use large filters which can eliminate these harmonics.

\subsection{Results of PWM Control for Inverter Switches}

The constant square wave control signal for the inverter switches can be divided into pulses with small width. These pulses are generated according to a comparison between $1 \mathrm{KHz}$ triangular wave and $50 \mathrm{~Hz}$ sinusoidal wave (PWM unipolar switching scheme). The generated control signals for both switches of inverter are shown in figure 4(e). Moreover, it should be note that the snubber capacitor in PWM control should be less than $5 \mu \mathrm{F}$. Figure 4(f) shows the resulted AC output from the inverter. This output is close to sinusoidal shape more than the square wave control. Therefore, the harmonic spectrum for this output voltage (as figure 4(h)) contains fewer harmonics which allow all the electrical equipment in the system, either the inverter itself or the loads connected to the inverter, to provide better performance.

\section{RESULTS OF REMOTE MONITORING AND CONTROL SYSTEM}

The GUI of the remote monitoring and control system prepared by Microsoft Visual Studio is displayed in figure 1(c) which also shows the standard e-mail sent from the system to the user. The implementation of this monitoring and control system depends mainly on the UART module in microcontroller. This module sends all system data and receives control commands to/from the personal computer. 


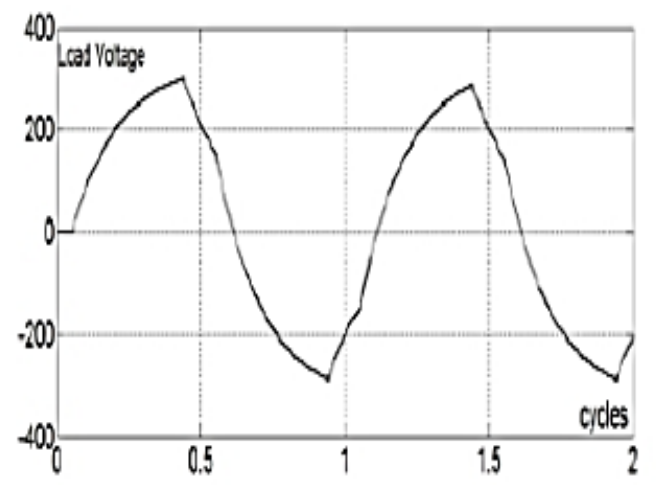

(a)

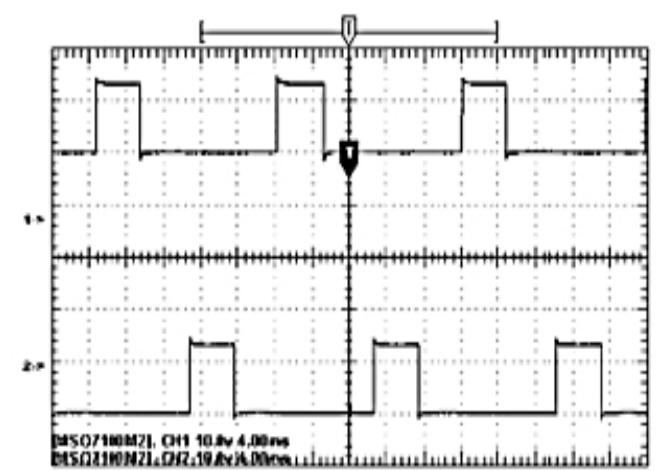

(c)

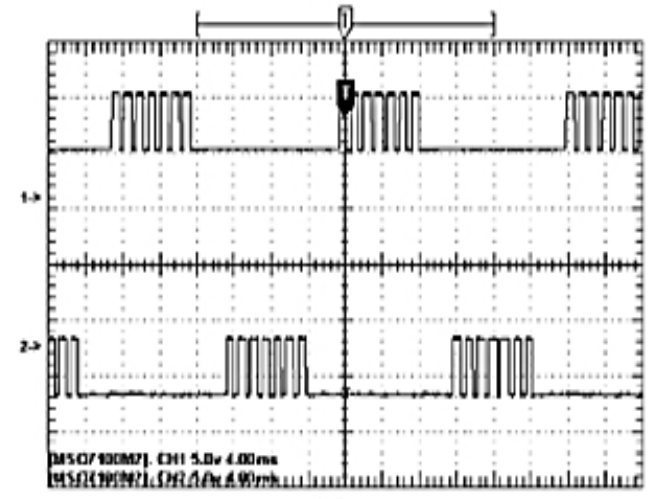

(e)

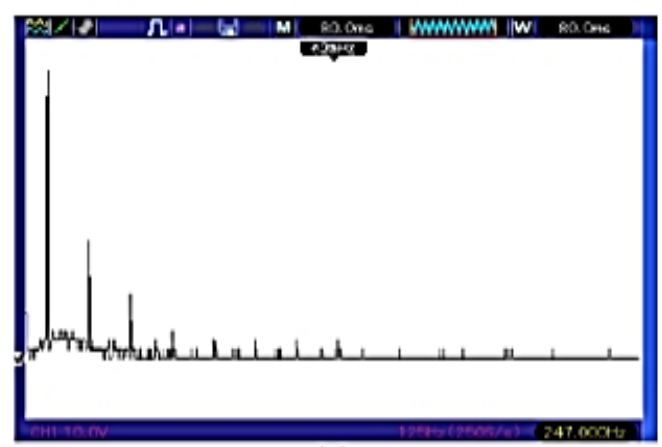

(g)

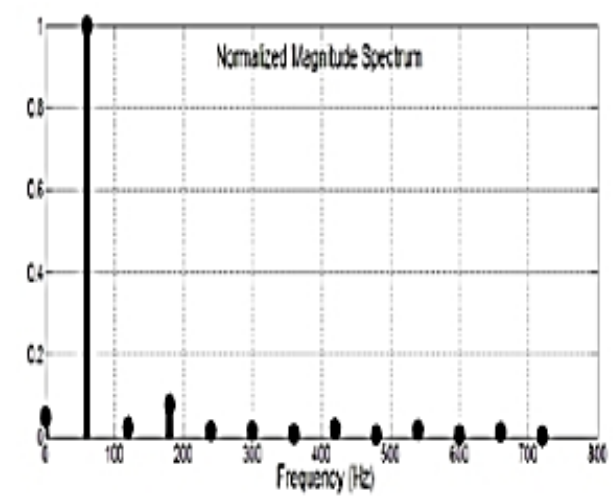

(b)

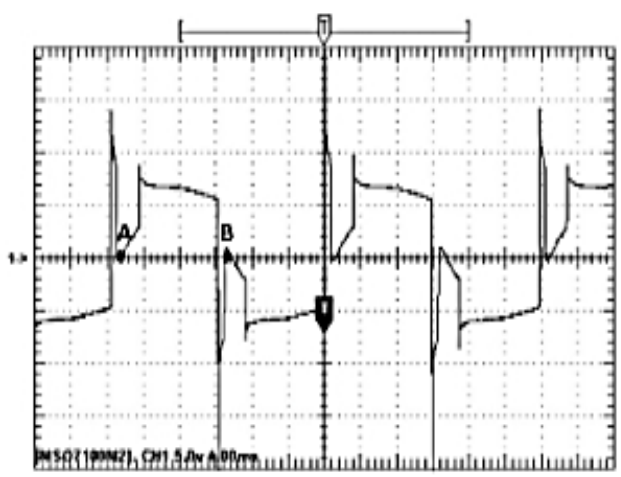

(d)

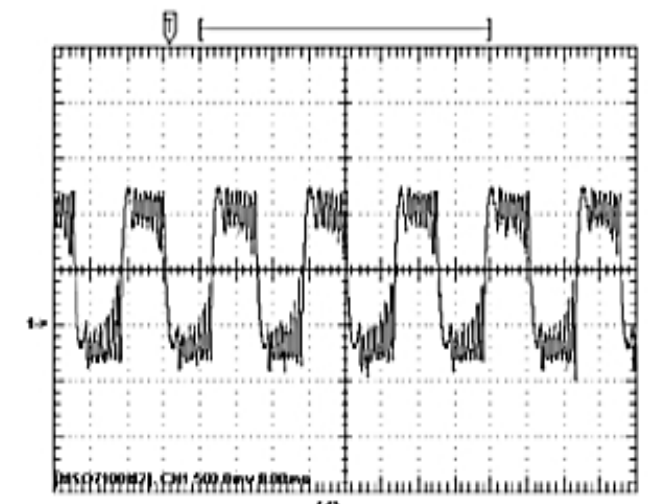

(f)

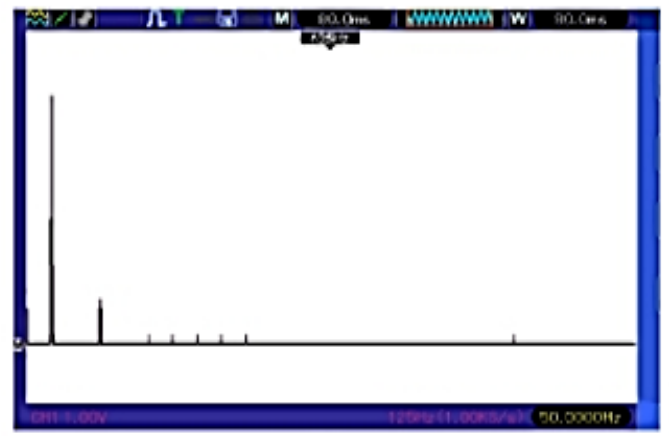

(h)

Figure 4 Waveforms of Result 


\section{CONCLUSION}

Design and implementation of economical smart push pull inverter are presented in details in this paper. The total cost of $2.5 \mathrm{Kw}$ inverters in [31] reaches up to $\$ 1800$. So the cost of the proposed inverter reduced by more than $50 \%$. The scheme implementation at low cost was demonstrated. The paper provides impressive results based on the comparison between the practical results and results of the state space modeling of the system. Moreover, this inverter can be used in smart systems depending on its capabilities to contact with the user either by GUI or e-mail. A visual environment is included in the designed system to facilitate its monitoring and control. Finally, this system achieves a simple method to operate the PV modules near its maximum power point

\section{REFERENCES}

[1] Teraya,D., Masukawa, S. and Iida, S. "Inverter for Interchangeable Use as Current Source Inverter and Voltage Source," Electrical Engineering in Japan, Vol. 183, No. 4, 2013.

[2] Lidozzi, A., Solero, L., Bifaretti, S., and Crescimbini, F. "Sinusoidal Voltage Shaping of Inverter-Equipped Stand-Alone Generating Units," IEEE Transactions on Industrial Electronics, Vol. 62 , Iss. 6, pp. 35573568, June 2015

[3] Jithesh, M., and Prawin, A. "Design and Analysis of a Single Phase Unipolar Inverter Using Sliding Mode Control," International Journal of Engineering and Advanced Technology (IJEAT), Vol. 2, Issue 2, 2012

[4] Adhikari, N., Singh, B., Vyas, A., Chandra, A., and Al-Haddad, K. "Analysis and design of isolated solar-PV energy generating system," IEEE Annual Meeting on IAS, pp. 1-6, 2011.

[5] Chan, C. K., Cheng, K. W. E., and Ho, S. L. "Half-bridge converter based on switched-capacitor resonance without using deadtime control for automotive applications," IET Power Electronics, Vol.4, Iss 6, pp. 657662, July 2011

[6] Fazeli, M., Ekanayake, J. B., Holland, P. M., and Igic, P. "Exploiting PV Inverters to Support Local Voltage-A Small-Signal Model," IEEE Transactions on Energy Conversion, Vol.29, Iss. 2, pp. 453-462, June 2014

[7] Dalci, K., Gulez, K., and Cansever, G. "The design of a push-pull switch mode power supply for AC drives," IEEE Annual Conference on IECON of, Vol. 2, pp. $1201-1206,2004$

[8] Kapadia, N., Patel, A., and Kapadia, D. "Simulation and Design of Low cost Single Phase Solar Inverter," International Journal of Emerging Technology and Advanced Engineering, Vol 2, Issue 1, February 2012

[9] Caixeiro Mattos, F., Lacerda, V. S., Valle, R. L., Ferreira, A.A., Barbosa, P. G., and Braga, H. A. C. "Contribution To The Study Of A SinglePhase And Single Stage Photovoltaic System," IEEE Latin America Transactions, Vol. 13, Iss. 5, pp. 1265-1271, May 2015

[10] Skvarenine, T. "The Power Electronics Handbook," CRC PRESS, 2nd edition, 2002

[11]Martino, M., Citro, C., Rouzbehi, K., and Rodriguez, P. "Efficiency Analysis of Single-Phase Photovoltaic Transformer-less Inverters," International Conference on Renewable Energies and Power Quality (ICREPQ'12), 2012

[12] Hagiwara, M., and Akagi, H. "Experiment and Simulation of a Modular Push-Pull PWM Converter for a Battery Energy Storage System," IEEE Transactions on Industry Applications, Vol. 50, Iss. 2, pp. 1131-1140, April 2014

[13] Shema, S., Daut, I., Irwanto, M., Shatri, C., Syafawati, N., and Ashbahani, N. "Study of inverter design and topologies for photovoltaic system," IEEE Int. Conf. on INECCE , PP. 501 - 504, June 2011

[14] Otero-De-Leon, R., and Mohan, N. "A push-pull DC-AC high frequency power electronics transformer for photovoltaic applications," IEEE Conference on Industrial Electronics Society, pp. 1131 - 1136, 2014

[15] Jianqiang, W., Jingxin, L. and Weige, Z. "Interleaved push-pull converter with very low input and high output," IEEE Int. Conf. on PEITS, Vol. 3, pp. $247-249,2009$

[16] Shungang, X. "Design of photovoltaic high frequency link inverter based on push-pull forward converter," IEEE Int. Conf. on ICCCAS, pp. 593 596,2010
[17]Mukhtar, S. M., Saad, A., and Hanafi, N. "A high efficiency microcontroller-based step-up push-pull DC-DC converter for PV inverter," IEEE Int. Conf. on PECon, pp. 141 - 145, 2010

[18] Kushwaha, R., Saha, T. K., Barman, J. C. and Dey, J. "Analysis and design of 2 DOF control of push-pull converter used for standalone PV system," IEEE Int. Conf. on Renewable Energy Congress (IREC), March 2015

[19] Yin, L., Zhao, Z., Lu, T., Yang, S., and Zou, G. "An Improved DC-Link Voltage Fast Control Scheme for a PWM Rectifier-Inverter System," IEEE Transactions on Industry Applications, Vol.50, Iss. 1, pp. 462-473, Feb. 2014

[20]Wu, T., Wang, S., Kuo, C., and Lee, K. "Design and implementation of a push-pull phase-shifted bi-directional inverter with a dsPIC controller," IEEE Int. Conf. on PEDS, pp. 728 - 733, 2009

[21] Kim, Y. C., Jin, L., and Choi, J. "Direct Digital Control of Single-Phase AC/DC PWM Converter System”, Journal of Power Electronics, Vol. 10, No. 5, September 2010

[22]Ramamurthy, G. "Handbook of Electrical Power Distribution," Universities Press, 1st Edition, 2004

[23] Linden, D., Reddy, T., "Handbook of Batteries 3rd Edition," McGrawHill, 3rd edition, 2002.

[24]Lynn, P. "Electricity from Sunlight: An Introduction to Photovoltaic," John Willy, 1st Edition, 2010.

[25] Schwarzer, U., and Doncker, D. "Design and implementation of a driver board for a high power and high frequency IGBT inverter," IEEE Int. Conf. on Power Electronics, Vol. 4, pp. 1907 - 1912, 2002

[26] Islam, M., and Mekhilef, S. "High efficiency transformerless MOSFET inverter for grid-tied photovoltaic system," IEEE Int. Conf. on APEC, 2014

[27]Hart, D. W. "Power Eelectronics," McGraw-Hill Companies, 1st edition, 2010

[28]Chokhawala, R., and Sobhani, S. "Switching Voltage Transient Protection Schemes for High-current IGBT Modules," IEEE Trans. Industry applications, vol. 31, no. 2, pp. 256-263, 2011

[29] Chitode, J. "Power Electronics" Technical Publication Pune, 3rd edition, 2008

[30]Lee, J., Chuah, Y., and Chai C. "A Multilevel Home Security System (MHSS)," International Journal of Smart Home, Vol. 7, No. 2, March, 2013.

[31] Mayer, J. N., Philipps S., Hussein, N. S., Schlegl, T., and Senkpiel, C. "Current and Future Cost of Photovoltaics Study," Agora Energiewende, February 2015 .

\section{APPendix: The Exact Costs of The Proposed INVERTER'S COMPONENTS}

1- The Exact Costs of Power Circuit components

\begin{tabular}{l|c} 
Item & Price in US Dollar \\
\hline Power transformer & 250 \\
\hline IGBT switches and Heat Sinks & 310 \\
\hline Connectors & 7.5 \\
\hline Cables & 4 \\
\hline Circuit Breaker and Fuses & 10 \\
\hline Fans & 4 \\
\hline Total & 585.5
\end{tabular}

\section{2- The Exact Costs of Control and Driver Circuit} Components

\begin{tabular}{l|c} 
Item & Price in US Dollar \\
\hline Control Circuit Board & 12 \\
\hline Volt Sensor & 4 \\
\hline Control Circuit Board & 7 \\
\hline Total & 23
\end{tabular}

